Check for updates

Cite this: Phys. Chem. Chem. Phys., $2021,23,12600$

\section{Understanding the remarkable difference in liquid crystal behaviour between secondary and tertiary amides: the synthesis and characterisation of new benzanilide-based liquid crystal dimers $\uparrow$}

\author{
Grant J. Strachan, (D) William T. A. Harrison, (D) John M. D. Storey and \\ Corrie T. Imrie (iD *
}

\begin{abstract}
A number of liquid crystal dimers have been synthesised and characterised containing secondary or tertiary ( $N$-methyl) benzanilide-based mesogenic groups. The secondary amides all form nematic phases, and we present the first example of an amide to show the twist-bend nematic $\left(\mathrm{N}_{\mathrm{TB}}\right)$ phase. Only two of the corresponding $\mathrm{N}$-methylated dimers formed a nematic phase and with greatly reduced nematic-isotropic transition temperatures. Characterisation using 2D ROESY NMR experiments, DFT geometry optimisation and $\mathrm{X}$-ray diffraction reveal that there is a change in the preferred conformation of the benzanilide core on methylation, from $Z$ to $E$. The rotational barrier around the $\mathrm{N}-\mathrm{C}(\mathrm{O})$ bond has been measured using variable temperature ${ }^{1} \mathrm{H}$ NMR spectroscopy. This dramatic change in shape accounts for the remarkable difference in liquid crystalline behaviour between these secondary and tertiary amide-based materials.
\end{abstract}

Received 12th March 2021, Accepted 12th April 2021 DOI: $10.1039 / d 1 c p 01125 a$ rsc.li/pccp

\section{Introduction}

The great majority of low molar mass liquid crystals consist of molecules containing a single semi-rigid, mesogenic core attached to which are one or two alkyl chains. ${ }^{1}$ In essence, the interactions between the mesogenic units promote liquid crystal behaviour whereas the role of the chains is to reduce the melting point, so making the liquid crystal behaviour accessible. The mesogenic unit normally consists of phenyl rings connected through short unsaturated linkages, often ester or imine groups. By comparison, the amide group is relatively uncommon in low molar mass liquid crystals (LCs) although it is found in technologically important liquid crystal polymers including, most notably, Kevlar. ${ }^{1}$ In this paper we address the fundamental question, why is the amide group not used more widely in the design of mesogenic units found in low molar mass liquid crystals?

Amides are classified as primary $\left(1^{\circ}\right)$, secondary $\left(2^{\circ}\right)$, or tertiary $\left(3^{\circ}\right)$, depending on the nature of the $N$-substituents, as shown in Fig. 1. Our focus is the use of the amide link in constructing the mesogenic unit and hence, the discussion is restricted to $2^{\circ}$ and $3^{\circ}$ amides. Early work recognised that the

Department of Chemistry, University of Aberdeen, Aberdeen, Scotland, UK.

E-mail: c.t.imrie@abdn.ac.uk

$\dagger$ Electronic supplementary information (ESI) available. CCDC 2016868 and 2016869. For ESI and crystallographic data in CIF or other electronic format see DOI: $10.1039 / \mathrm{d} 1 \mathrm{cp} 01125 \mathrm{a}$ inclusion of amide groups has a detrimental effect on liquid crystallinity. ${ }^{2}$ It was found, however, that $2^{\circ}$ amides could form liquid crystal phases, although these materials showed high melting points which were attributed to the presence of strong hydrogen bonding. ${ }^{3}$ Careful molecular design using a selection of suitable lateral substituents and terminal groups attached to the mesogenic units allowed the melting point to be manipulated and a range of calamitic ${ }^{4-13}$ and bent-core ${ }^{14-18}$ liquid crystalline materials based around secondary amide groups have been reported. These systems tend to predominantly form smectic phases, again attributed to intermolecular hydrogen bonding between the amide groups. Indeed, the use of amide groups in structures such as benzene tricarboxamides (BTA), ${ }^{19-22}$ hydrazine derivatives, ${ }^{23-28}$ or peptide residues ${ }^{29-31}$ promotes columnar liquid crystal phases in which hydrogen bonding stabilises the columns.

In terms of molecular design, it would appear desirable to eliminate the strong hydrogen bonding between the amide groups, with a view to reducing melting temperatures and to promote nematic behaviour. This may be achieved by replacing the hydrogen atom on the nitrogen with a methyl group, giving a tertiary amide (Fig. 1). Surprisingly, there have been very few examples of liquid crystals containing tertiary amides. Examples of these include discotic liquid crystals with amide groups incorporated into a fused ring structure ${ }^{32-34}$ and mesogens featuring an $N, N$-dialkyl amide terminal group, ${ }^{35}$ as well as the use of $N$-methyl amides as linking groups to attach a chiral aliphatic tail to an 


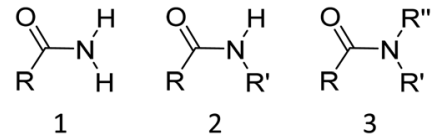

Fig. 1 The structure of primary $\left(1^{\circ}\right)$, secondary $\left(2^{\circ}\right)$ and tertiary $\left(3^{\circ}\right)$ amides.

aromatic core. ${ }^{36,37}$ Critically, we are not aware of any reports of tertiary amides being used in the construction of calamitic or bent core mesogenic units. Conventional wisdom attributes this surprising observation to the loss of hydrogen bonding between the molecules. ${ }^{14}$ This intuitively pleasing assumption appears not to have been questioned. Tertiary benzanilides are known, however, to show a marked preference for adopting the $E$ conformation $^{38-41}$ although this does not appear to have been taken into consideration when considering the absence of liquid crystalline behaviour.

In this work we investigate the difference in phase behaviour between liquid crystal dimers containing $2^{\circ}$ and $3^{\circ}$ benzanilidebased mesogenic units to establish the effect of $N$-alkylation on liquid crystalline behaviour. A liquid crystal dimer is a molecule containing two mesogenic units attached by a flexible spacer. ${ }^{42,43}$ In a symmetric dimer, the two mesogenic units are the same whereas they are different in a non-symmetric dimer. The advantage of using this molecular architecture to address our central question is that we know that moving from $2^{\circ}$ to $3^{\circ}$ amides we will see a marked reduction in the stability of the liquid crystal phase, but this may be counteracted in the dimer by careful design of the second mesogenic unit and by varying the length of the spacer. Furthermore, if an odd-membered spacer is chosen, these dimers, on average, will have a bent molecular shape and the potential to exhibit the highly topical twist-bend nematic, $\mathrm{N}_{\mathrm{TB}}$, phase. ${ }^{42,44-47}$ In the $\mathrm{N}_{\mathrm{TB}}$ phase the director forms a conical helix and is tilted with respect to the helical axis. This chiral structure forms spontaneously and so the induced twist may be either left- or right-handed and equal amounts of both types of helix are expected. This chirality is observed even though the constituent molecules are achiral. The double degeneracy may be removed by the inclusion of intrinsic molecular chirality and the chiral twist-bend nematic phase is observed. ${ }^{48}$ The general structure of the non-symmetric dimers reported here is shown in Table 1. Each contain an odd-membered spacer linked to one mesogenic unit via an ether link and to the other by a methylene group. This ensures the necessary molecular curvature to potentially exhibit the $\mathrm{N}_{\mathrm{TB}}$ phase. ${ }^{49-52}$ The structural changes shown in Table 1 are intended to change the shape anisotropy of the molecule and allow the transition temperatures to be manipulated. The role of the lateral methyl group is to disrupt, at least to some extent, lateral interactions in an attempt to reduce the melting temperature. The key question to address is how does $\mathrm{N}$-methylation change the shapes of these molecules, and specifically, in terms of the conformation of the amide? This has been studied using a combination of 2D NOESY and ROESY NMR experiments; single crystal X-ray diffraction; and DFT geometry optimisation. We also investigate the effect of $\mathrm{N}$-methylation on the rotational barrier around the $\mathrm{N}-\mathrm{C}(\mathrm{O})$ bond using variable temperature ${ }^{1} \mathrm{H}$ NMR spectroscopy.
Table 1 The structures of the amide-based dimers reported

\begin{tabular}{|c|c|c|c|c|}
\hline Compound & $\mathrm{A}$ & B & $n$ & $\mathrm{X}$ \\
\hline $1 \mathrm{a}$ & $\mathrm{Br}$ & $\mathrm{Br}$ & 6 & $\mathrm{H}$ \\
\hline $1 b$ & $\mathrm{Br}$ & $\mathrm{Br}$ & 6 & $\mathrm{CH}_{3}$ \\
\hline $2 a$ & $\mathrm{Br}$ & $\mathrm{CN}$ & 6 & $\mathrm{H}$ \\
\hline $2 b$ & $\mathrm{Br}$ & $\mathrm{CN}$ & 6 & $\mathrm{CH}_{3}$ \\
\hline $3 \mathbf{a}$ & $\mathrm{CN}$ & $\mathrm{CN}$ & 6 & $\mathrm{H}$ \\
\hline $3 \mathbf{b}$ & $\mathrm{CN}$ & $\mathrm{CN}$ & 6 & $\mathrm{CH}_{3}$ \\
\hline $4 a$ & $\mathrm{Ph}-\mathrm{CN}$ & $\mathrm{CN}$ & 6 & $\mathrm{H}$ \\
\hline $4 b$ & $\mathrm{Ph}-\mathrm{CN}$ & $\mathrm{CN}$ & 6 & $\mathrm{CH}_{3}$ \\
\hline $5 \mathbf{a}$ & $\mathrm{Ph}-\mathrm{CN}$ & $\mathrm{CN}$ & 10 & $\mathrm{H}$ \\
\hline $5 b$ & $\mathrm{Ph}-\mathrm{CN}$ & $\mathrm{CN}$ & 10 & $\mathrm{CH}_{3}$ \\
\hline $6 a$ & $\mathrm{Ph}-\mathrm{CN}$ & $\mathrm{Ph}-\mathrm{CN}$ & 10 & $\mathrm{H}$ \\
\hline $6 b$ & $\mathrm{Ph}-\mathrm{CN}$ & $\mathrm{Ph}-\mathrm{CN}$ & 10 & $\mathrm{CH}_{3}$ \\
\hline
\end{tabular}

\section{Experimental}

Schemes 1-4 provide an overview of the synthetic routes used to prepare the benzanilide-based dimers (Fig. 2). The syntheses were carried out according to literature methods, and full experimental details and structural characterisation data are given in the ESI. $\dagger$

\section{Thermal behaviour}

The transitional behaviour of the materials was studied using differential scanning calorimetry (DSC) with a Mettler Toledo DSC3 differential scanning calorimeter equipped with a TSO 801RO sample robot and calibrated with indium and zinc standards. The heating and cooling rates were $10{ }^{\circ} \mathrm{C} \min ^{-1}$ and the transition temperatures and their associated enthalpy changes were extracted from heating traces unless otherwise noted.

Polarised optical microscopy (POM) was used to identify the liquid crystal phases observed using an Olympus BH2 polarising optical microscope equipped with a Linkam TMS 92 hot stage. The samples were prepared using untreated glass slides.

\section{Rotational barriers}

Measurement of rotational energy barriers were carried out using variable temperature ${ }^{1} \mathrm{H}$ NMR spectroscopy on a Bruker Ascend $600 \mathrm{MHz}$ spectrometer with a cryoprobe and VT unit. Lineshape analysis was performed using the DNMR module in the Bruker TOPSPIN package.

\section{X-ray crystallography}

Single crystals of compounds $\mathbf{4} \mathbf{b}$ and $\mathbf{5 b}$ in the forms of colourless blocks were grown from a 2:1 solution of toluene and chloroform, and intensity data were collected on a Rigaku AFC11 CCD diffractometer ( $\mathrm{Cu} \mathrm{K} \alpha$ radiation, $\lambda=1.54184 \AA$ ) at $100 \mathrm{~K}$. The structures were solved by 'dual space' methods using SHELXT and the structural models were completed and optimised by refinement against $|F|^{2}$ with SHELXL-2014. ${ }^{53}$ The benzene rings were modelled as rigid hexagons $(\mathrm{C}-\mathrm{C}=1.39 \AA)$ 


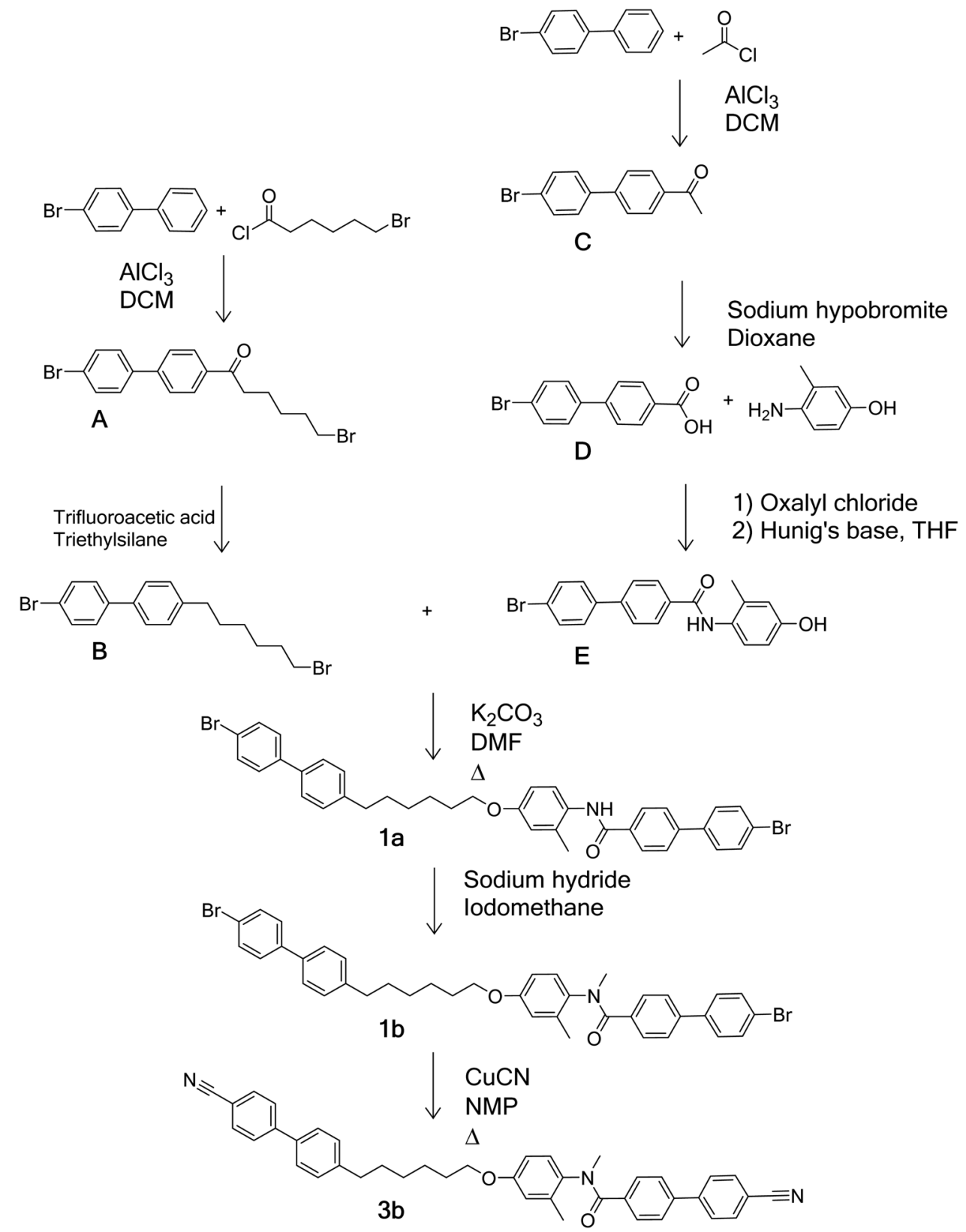

Scheme 1 Synthesis of compounds $\mathbf{1 a}, \mathbf{1} \mathbf{b}$, and $\mathbf{3 b}$

and the $\mathrm{H}$ atoms were placed geometrically $(\mathrm{C}-\mathrm{H}=0.95-0.98 \AA)$ and refined as riding atoms. The structure of $\mathbf{4 b}$ refined well but the data and refinement quality for $\mathbf{5 b}$ are very poor with unresolvable disorder in the decyl chains possibly indicative of an unmodelled supercell and only qualitative conclusions may be drawn for the latter structure. Crystal data for $4 \mathbf{b}$ : $\mathrm{C}_{47} \mathrm{H}_{41} \mathrm{~N}_{3} \mathrm{O}_{2}, M_{\mathrm{r}}=679.83$, monoclinic, space group $C c$ (No. 9), $a=31.5211$ (4), $b=14.7867$ (2), $c=33.4555$ (5) ̊, $\beta=112.551$ (2) ${ }^{\circ}$, $V=14401.1(4) \AA^{3}, Z=16, R(F)=0.078$ [22766 reflections with $I>2 \sigma(I)], \mathrm{w} R\left(F^{2}\right)=0.222$ (26665 reflections), CCDC deposition number $=2016868 . \dagger$

Crystal data for 5b: $\mathrm{C}_{51} \mathrm{H}_{49} \mathrm{~N}_{3} \mathrm{O}_{2}, M_{\mathrm{r}}=735.93$, monoclinic, space group $P n$ (No. 7), $a=21.61054$ (14), $b=13.81870$ (7), $c=28.98487$ (19) $\AA, \beta=110.2699(7)^{\circ}, V=8119.69$ (9) $\AA^{3}, Z=8$, $R(F)=0.186$ [24423 reflections with $I>2 \sigma(I)], \mathrm{w} R\left(F^{2}\right)=0.455$ (26446 reflections), CCDC deposition number $=2016869$. $\dagger$

\section{Geometry optimisations}

Geometry optimisation was carried out using DFT calculations at the B3LYP-6-31G(d) level of theory with Gaussian09 software. ${ }^{54}$ Space-filling models were generated from the optimised geometries using the QuteMol package. ${ }^{55}$ Although ether-linked spacers have been found to have a gauche linkage in their lowest energy state, ${ }^{56}$ the energy difference between this and the all-trans conformation is small (ca. $\left.1 \mathrm{~kJ} \mathrm{~mol}^{-1}\right)$ and it is expected that the greater linearity of the all-trans state will be more favourable 


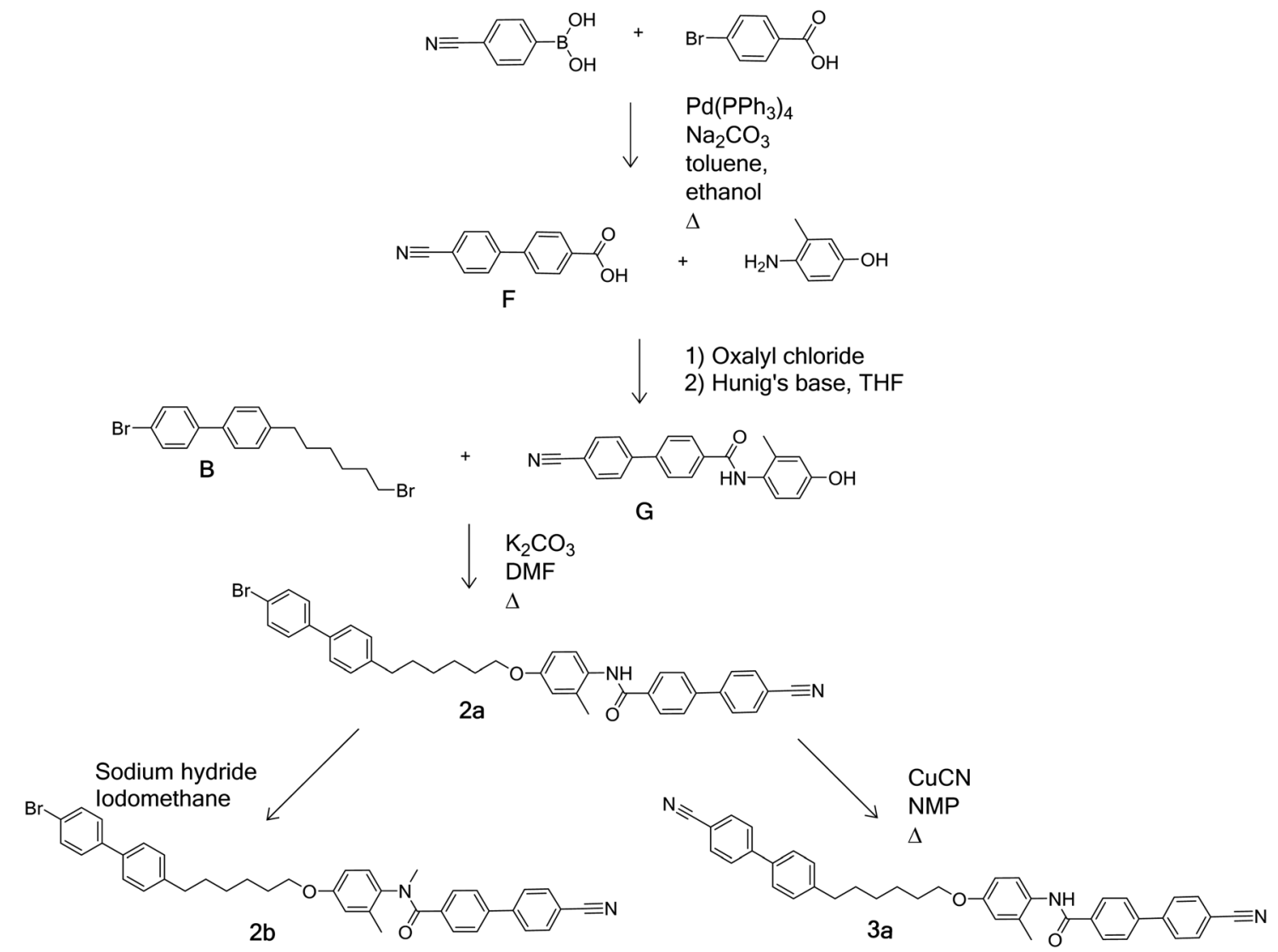

Scheme 2 Synthesis of compounds $\mathbf{2} \mathbf{a}, \mathbf{2} \mathbf{b}$, and $\mathbf{3 a}$.

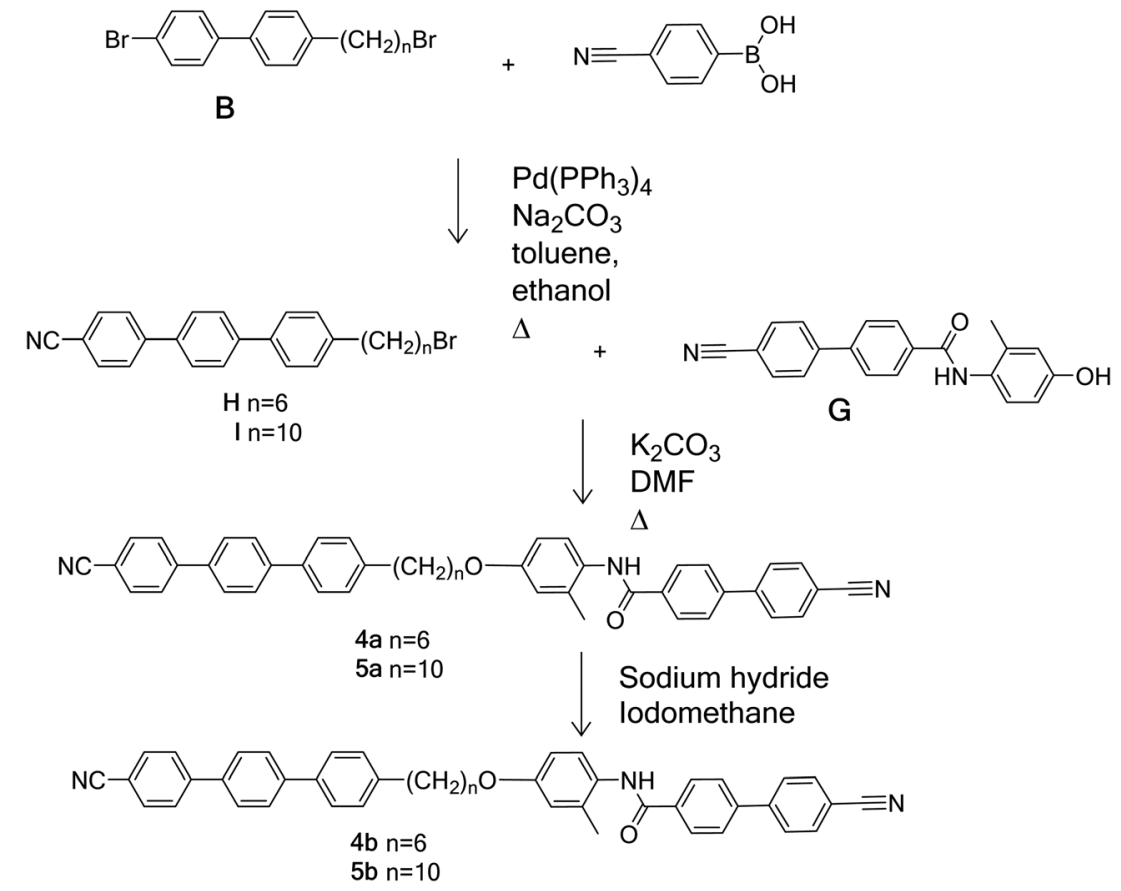

Scheme 3 Synthesis of compounds $\mathbf{4 a}, \mathbf{4 b}, \mathbf{5 a}$, and $\mathbf{5 b}$

within a liquid crystalline phase. ${ }^{57}$ Based on this, the geometry optimisations were carried out with the central spacer in the all-trans conformation. This assumption is in accord with similar studies. ${ }^{58}$ 


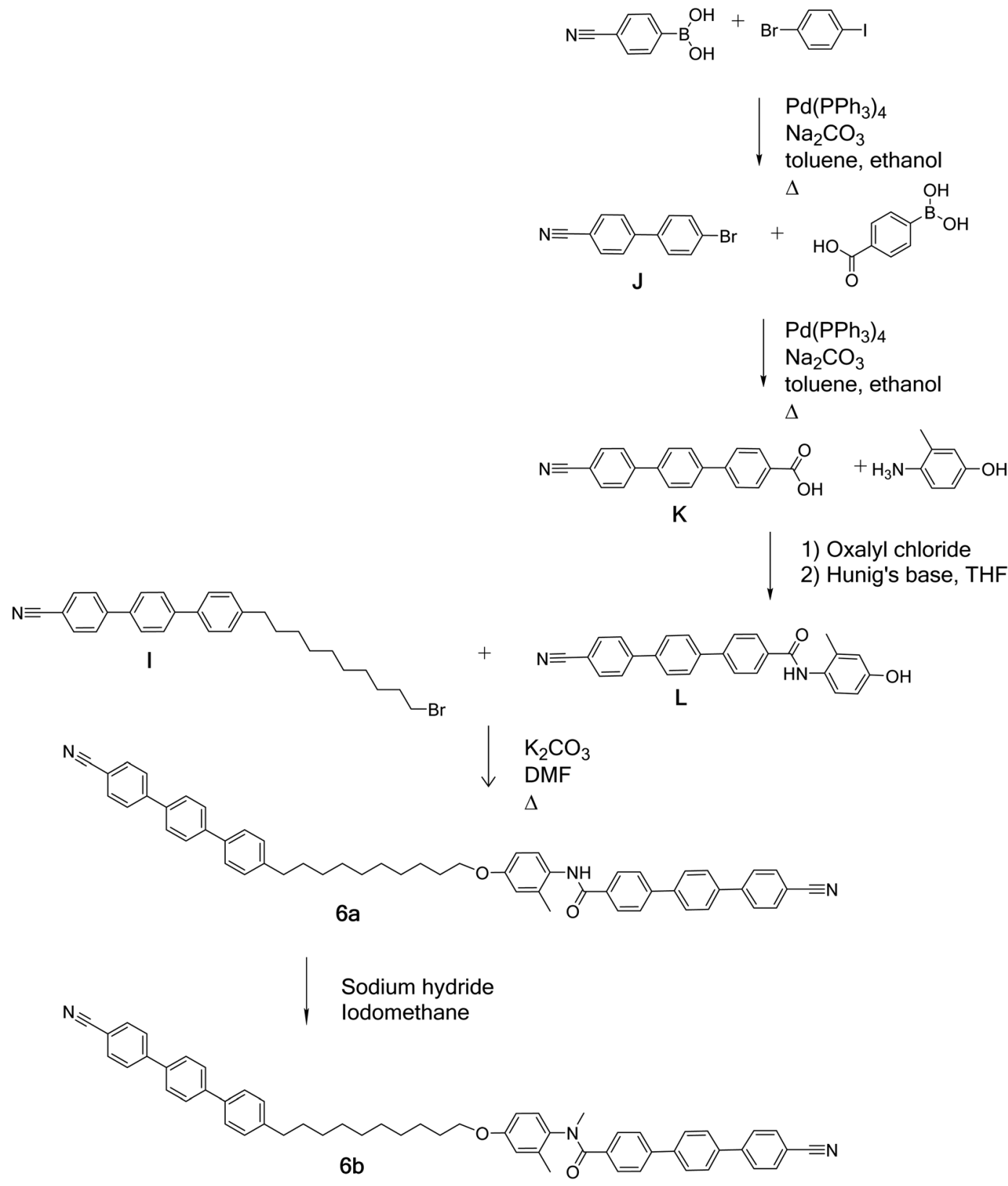

Scheme 4 Synthesis of compounds $\mathbf{6 a}$ and $\mathbf{6 b}$.

\section{Results and discussion}

\section{Phase behaviour}

The first set of dimers to be discussed contain two biphenyl units joined by a hexyloxy spacer and are divided into three groups based on their terminal groups. For each the $\mathrm{N}-\mathrm{H}$ and $N$-methyl versions are reported. Structures $\mathbf{1 a}$ and $\mathbf{1 b}$ have bromobiphenyl units at each end, $\mathbf{2 a}$ and $\mathbf{2 b}$ have one bromobiphenyl and one cyanobiphenyl unit, and $\mathbf{3 a}$ and $\mathbf{3 b}$ have two cyanobiphenyl units. The transitional properties of this group of dimers are listed in Table 2 . The three secondary amides (1a, 2a and 3a) display a conventional nematic, N, phase. Throughout this study nematic phases have been assigned on the basis of the observation of a schlieren optical texture containing two- and four-brush defects and which flashes when subjected to mechanical stress. A representative texture is given in Fig. 2. The scaled nematic-isotropic entropy changes are consistent with this assignment. ${ }^{56,59}$

The methylation of the amide nitrogen to form $3^{\circ}$ amides in all three cases led to a loss of liquid crystalline behaviour. All three $3^{\circ}$ benzanilides melted directly into the isotropic phase on heating and formed a glass on cooling $\left(T_{\mathrm{g}} 59{ }^{\circ} \mathrm{C}, 69{ }^{\circ} \mathrm{C}\right.$ and $51{ }^{\circ} \mathrm{C}$ for compounds $\mathbf{1 b}, \mathbf{2 b}$, and $\mathbf{3 b}$, respectively). This represents a reduction in the value of $T_{\mathrm{NI}}$ by at least $61{ }^{\circ} \mathrm{C}$ for $\mathbf{1 b}$ and $\mathbf{2 b}$ compared to the corresponding $2^{\circ}$ benzanilides, and of $101{ }^{\circ} \mathrm{C}$ for $\mathbf{3 b}$. These reductions appear too large to be associated with the anticipated change in molecular shape associated with the $N$-methyl group. ${ }^{60}$ 




Fig. 2 POM texture of compound $1 \mathrm{a}$ in the nematic phase at $190{ }^{\circ} \mathrm{C}$.

Table 2 The transition temperatures, transitional enthalpies and scaled entropies of $2^{\circ}$ compounds $\mathbf{1 a}, \mathbf{2} \mathbf{a}$ and $\mathbf{3} \mathbf{a}$ and $3^{\circ}$ compounds $\mathbf{1} \mathbf{b}, \mathbf{2} \mathbf{b}$, and $\mathbf{3} \mathbf{b}$

\begin{tabular}{lllllll}
\hline & $T_{\mathrm{CrN}} /{ }^{\circ} \mathrm{C}$ & $T_{\mathrm{NI}} /{ }^{\circ} \mathrm{C}$ & $\Delta H_{\mathrm{NI}} / \mathrm{kJ} \mathrm{mol}^{-1}$ & $\Delta S_{\mathrm{NI}} / R$ & & $T_{\mathrm{CrI}} /{ }^{\circ} \mathrm{C}$ \\
\hline $\mathbf{1 a}$ & 212 & $187^{a}$ & $0.77^{a}$ & $0.20^{a}$ & $\mathbf{1 b}$ & 126 \\
$\mathbf{2 a}$ & 188 & 199 & 0.66 & 0.17 & $\mathbf{2 b}$ & 138 \\
$\mathbf{3 a}$ & 186 & 224 & 1.11 & 0.27 & $\mathbf{3 b}$ & 123
\end{tabular}

${ }^{a}$ Taken from DSC cooling trace.

As a result of the dramatic loss of liquid crystallinity on $N$-methylation seen for the compounds listed in Table 2, changes to the basic dimer structure were made with the aim of increasing the potential transition temperatures to offset the effect of introducing the $N$-methyl group. Firstly, one of the cyanobiphenyl groups was replaced with a cyanoterphenyl unit to give $\mathbf{4 a}$, which in a conventional low molar mass liquid crystal can typically increase $T_{\mathrm{NI}}$ by around $150{ }^{\circ} \mathrm{C} .{ }^{61}$ The inclusion of the extra phenyl ring increased $T_{\mathrm{NI}}$ (Table 3 ) of $4 \mathbf{a}$ by $94{ }^{\circ} \mathrm{C}$ compared to that of 3a. In addition, on cooling the $\mathrm{N}$ phase of $4 \mathrm{a}$, a transition to the twist-bend nematic phase was seen at $130{ }^{\circ} \mathrm{C}$. This was most clearly observed for isolated droplets, for which the schlieren texture developed a blocky appearance (Fig. 3).

However, the $\mathrm{N}$-methylated material $\mathbf{4 b}$ again did not show any mesogenic behaviour. The material melted directly into the isotropic phase at $145{ }^{\circ} \mathrm{C}$ on the initial heat. On cooling, the sample formed a glass at $57{ }^{\circ} \mathrm{C}$ which indicates a reduction in the nematic-isotropic transition temperature of at least $261{ }^{\circ} \mathrm{C}$ compared to the corresponding $2^{\circ}$ benzanilide.

Given the change from a biphenyl to terphenyl end group was not sufficient to promote liquid crystalline behaviour in the $N$-methylated dimer $\mathbf{4 b}$, the length of the central spacer was increased to ten carbon atoms. The increase in the chain length was anticipated to suppress crystallisation possibly revealing

Table 3 The transition temperatures and transitional enthalpies of compounds $4 \mathrm{a}$ and $\mathbf{4 b}$

\begin{tabular}{llllll}
\hline & $T_{\mathrm{CrN}} /{ }^{\circ} \mathrm{C}$ & $T_{\mathrm{N}_{\mathrm{TB}}-\mathrm{N}} /{ }^{\circ} \mathrm{C}$ & $T_{\mathrm{NI}} /{ }^{\circ} \mathrm{C}$ & $\Delta H_{\mathrm{NI}} / \mathrm{kJ} \mathrm{mol}^{-1}$ & $\Delta S_{\mathrm{NI}} / R$ \\
\hline $\mathbf{4 a}$ & 208 & $130^{a b}$ & 329 & 4.08 & 0.82 \\
$\mathbf{4 b}$ & 145 & - & - & - & -
\end{tabular}

${ }^{a}$ Taken from DSC cooling trace. ${ }^{b}$ DSC transition appeared as a step change in the baseline.

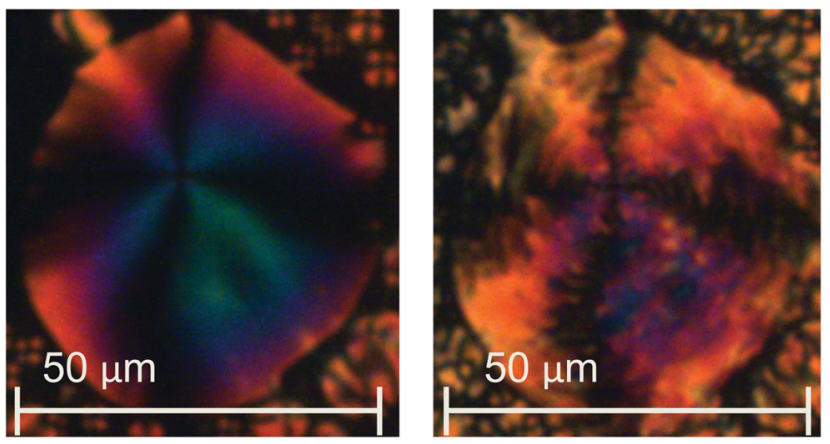

Fig. 3 POM texture of compound $4 \mathrm{a}$ in (left) the nematic phase at $136^{\circ} \mathrm{C}$ and (right) the twist-bend nematic phase at $96{ }^{\circ} \mathrm{C}$.

liquid crystalline behaviour. The non-methylated material 5a again showed a nematic phase, with a schlieren texture containing 2- and 4-point brush defects, and in addition a twist-bend nematic phase on cooling, for which the schlieren texture changed to include rope-like defects (Fig. 4). The value of $T_{\mathrm{NI}}$ for $\mathbf{5 a}$ (Table 4) is slightly lower than that of compound $\mathbf{4 a}$, and this may be attributed to the dilution of the mesogenic units arising from increasing the spacer length. The value of $T_{\mathrm{N}_{\mathrm{TB}} \mathrm{N}}$ for $\mathbf{5 a}$ is also slightly lower than that seen for $\mathbf{4 a}$, which may be attributed to an increased molecular flexibility which reduces molecular curvature. $^{56}$ Of particular significance is the effect molecular flexibility has on the tendency to crystallise; thus, 5a can be cooled to $101{ }^{\circ} \mathrm{C}$ prior to crystallisation, whereas $4 \mathrm{a}$ crystallises at $208{ }^{\circ} \mathrm{C}$. The very extensive supercooling of the isotropic phase of 5b is now sufficiently large to reveal a nematic phase which crystallised at $81{ }^{\circ} \mathrm{C}$. The entropy change associated with the nematic-isotopic transition (Table 3 ) is very small and we will return to this observation later. The reduction in $T_{\mathrm{NI}}$ on methylating $\mathbf{5 a}$ to give $\mathbf{5 b}$ is $219{ }^{\circ} \mathrm{C}$.

In an attempt to increase $T_{\mathrm{NI}}$ for the $3^{\circ}$ amide $5 \mathbf{b}$ the remaining cyanobiphenyl unit was replaced with a second cyanoterphenyl fragment. The corresponding $2^{\circ}$ amide $6 \mathbf{a}$ melts into the nematic
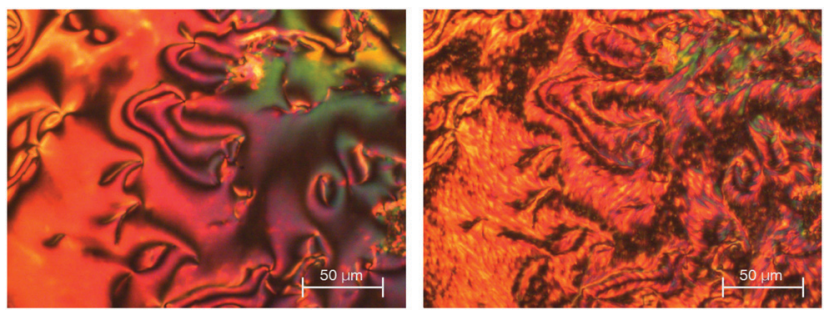

Fig. 4 POM texture of compound $\mathbf{5 a}$ in (left) the nematic phase at $140{ }^{\circ} \mathrm{C}$ and (right) the twist-bend nematic phase at $114^{\circ} \mathrm{C}$

Table 4 The transition temperatures and transitional enthalpies of compounds $\mathbf{5 a}$ and $\mathbf{5 b}$

\begin{tabular}{|c|c|c|c|c|c|c|}
\hline & $T_{\mathrm{CrN}} /{ }^{\circ} \mathrm{C}$ & $T_{\mathrm{N}_{\mathrm{TB}}-\mathrm{N}} /{ }^{\circ} \mathrm{C}$ & $\Delta H_{\mathrm{N}_{\mathrm{TB}}-\mathrm{N}} / \mathrm{kJ} \mathrm{mol}^{-1}$ & $T_{\mathrm{NI}} /{ }^{\circ} \mathrm{C}$ & $\Delta H_{\mathrm{NI}} / \mathrm{kJ} \mathrm{mol}^{-1}$ & $\Delta S_{\mathrm{NI}} / R$ \\
\hline $5 a$ & 195 & $123^{b}$ & $\sim 0^{a}$ & 303 & 4.02 & 0.84 \\
\hline $5 b$ & 146 & - & - & $84^{b}$ & $0.22^{b}$ & 0.07 \\
\hline
\end{tabular}

${ }^{a}$ DSC transition appeared as step change in baseline. ${ }^{b}$ Taken from DSC cooling trace. 
Table 5 The transition temperatures and transitional enthalpies of compounds $\mathbf{6 a}$ and $\mathbf{6 b}$

\begin{tabular}{lllll}
\hline & $T_{\mathrm{CrN}} /{ }^{\circ} \mathrm{C}$ & $T_{\mathrm{NI}} /{ }^{\circ} \mathrm{C}$ & $\Delta H_{\mathrm{NI}} / \mathrm{kJ} \mathrm{mol}^{-1}$ & $\Delta S_{\mathrm{NI}} / R$ \\
\hline $\mathbf{6 a}$ & 186 & 386 & 5.6 & 1.0 \\
$\mathbf{6 b}$ & 177 & $142^{a}$ & 0.68 & 0.20
\end{tabular}

${ }^{a}$ Taken from DSC cooling trace.

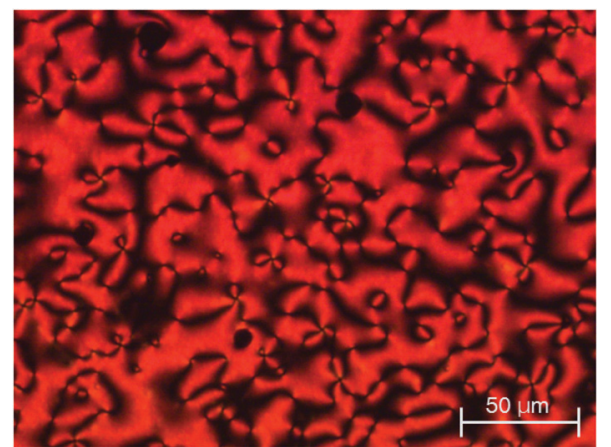

Fig. 5 POM texture of compound $6 \mathbf{b}$ in the nematic phase at $190{ }^{\circ} \mathrm{C}$.

phase at $186{ }^{\circ} \mathrm{C}$ and clears at $388{ }^{\circ} \mathrm{C}$ (Table 5). The inclusion of the second cyanoterphenyl group promotes crystallisation and precludes the observation of the twist-bend nematic phase. ${ }^{62}$ The $N$-methylated dimer $\mathbf{6 b}$ melted directly into the isotropic phase at $179{ }^{\circ} \mathrm{C}$, and on cooling formed a nematic phase at $161{ }^{\circ} \mathrm{C}$ (Fig. 5), and vitrified at $44{ }^{\circ} \mathrm{C}$ (Table 5). On reheating, a glass transition occurred at $47{ }^{\circ} \mathrm{C}$, followed by cold crystallisation at $88{ }^{\circ} \mathrm{C}$, a crystal-crystal transition at $103{ }^{\circ} \mathrm{C}$, and the sample melted into the isotropic phase at $177^{\circ} \mathrm{C}$. The reduction in $T_{\mathrm{NI}}$ on methylating $6 \mathbf{a}$ to give $\mathbf{6 b}$ was $244{ }^{\circ} \mathrm{C}$. The value of $T_{\mathrm{NI}}$ of $\mathbf{6 b}$ was $77^{\circ} \mathbf{C}$ higher than that of $\mathbf{5 b}$, which is consistent with the inclusion of an additional phenyl ring (Table 5).

It is very clear that the structural change from a $2^{\circ}$ to a $3^{\circ}$ amide is associated with very dramatic changes in liquid crystalline behaviour (Tables $2-5$ ). The reduction observed in $T_{\mathrm{NI}}$ cannot be accounted for simply in terms of the addition of a lateral methyl group. In itself this is not a sufficiently large difference in shape to account for such dramatic decreases in $T_{\mathrm{NI}}$, see Fig. 6 . As noted earlier, conventional wisdom accounts for the change in terms of the loss of hydrogen bonding. This seems unlikely, however, because if compared to similar ester-, and imine-based compounds for which hydrogen bonding is not an issue, the transition temperatures are much lower than would be expected.

In an attempt to understand this remarkable difference in behaviour between the $2^{\circ}$ and $3^{\circ}$ amides we need to establish if the molecular configuration about the nitrogen changes when a
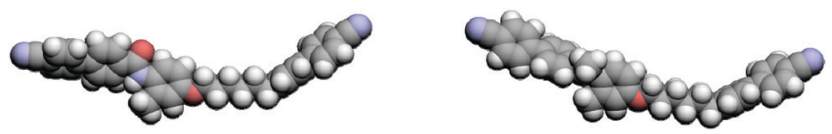

Fig. 6 Space filling models of $3 \mathbf{a}$ and $\mathbf{3 b}$ showing the effect of $N$ methylation on molecular shape.

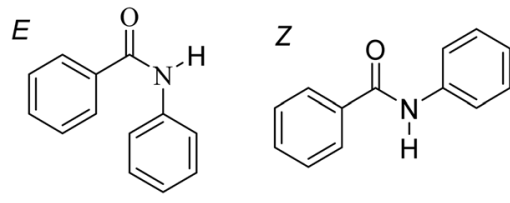

Fig. $7 \quad E$ and $Z$ conformations of benzanilide.

methyl group is added. The central $\mathrm{C}-\mathrm{N}$ bond of an amide group has partial double bond character as a result of delocalisation of the lone pair from the nitrogen, and this leads to the possibility of $E$ and $Z$ isomers, see Fig. 7. For most amides, the $Z$ isomer is lower in energy and hence is the preferred conformer.

To determine the amide conformations adopted by the $2^{\circ}$ and $3^{\circ}$ amides reported here, 2D NOESY and ROESY NMR spectra were collected for each compound. Unlike most NMR experiments, these experiments show interactions that occur between atoms that are close together in space, rather than connected by chemical bonds. The spectra of all the $2^{\circ}$ amides should show one set of correlations, see Fig. 8(A), whereas the spectra of the $3^{\circ}$ amides should show a different set of signals, see Fig. 8(B). The ROESY NMR spectra of $\mathbf{3 a}$ and $\mathbf{3 b}$ are shown in Fig. 9 and 10, respectively. For the $2^{\circ}$ amides, interactions are seen between the $\mathrm{N}-\mathrm{H}$ and the aryl methyl, shown in Fig. 8(A). In addition, there is a cross-peak between the $\mathrm{N}-\mathrm{H}$ and the aromatic protons adjacent to the carbonyl group. This cross-peak would be expected for the $Z$-conformation. Based on these interactions, the $2^{\circ}$ amides are assigned as being in the $Z$ conformation.

The ROESY spectra of the $3^{\circ}$ amide compounds, on the other hand, show a different set of interactions. The $N$-methyl has ROE cross-peaks with the aryl methyl, as well as the aromatic proton next to the nitrogen. However, it has no cross-peak with the aromatic protons next to the carbonyl. Instead, these aromatic protons now have a cross-peak with the aromatic methyl. This shows that the amide has switched conformations to the $E$-isomer.

This difference in the preferred conformation between the $2^{\circ}$ and $3^{\circ}$ amides is also predicted by quantum mechanical DFT calculations. Geometry optimisations of compound $4 \mathbf{a}$ in the $E$ - and $Z$-forms suggest that the $Z$ conformer is $15 \mathrm{~kJ} \mathrm{~mol}^{-1}$ lower in energy than the $E$ conformer, as would be expected. For 4b, however, the $E$-isomer is $9.8 \mathrm{~kJ} \mathrm{~mol}^{-1}$ lower in energy than the $Z$-isomer. This view is consistent with the extremely small value of $\Delta S_{\mathrm{NI}} / R$ seen for $\mathbf{5 b}$ (Table 4$)$. The kinked amide fragment increases the molecular biaxiality which reduces the change in orientational order at the nematic-isotropic transition (Fig. 11). ${ }^{63,64}$

This preference for the $E$-isomer is found for all the $3^{\circ}$ amides. This view was confirmed using X-ray diffraction. The crystal
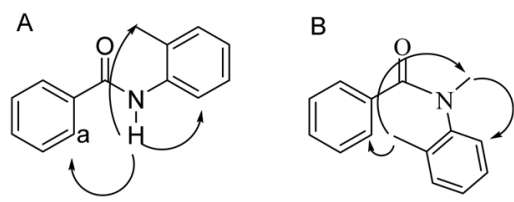

Fig. 8 (A) The ROE interactions seen in the $2^{\circ}$ amides. (B) The ROE interactions seen for the $3^{\circ}$ amides. 


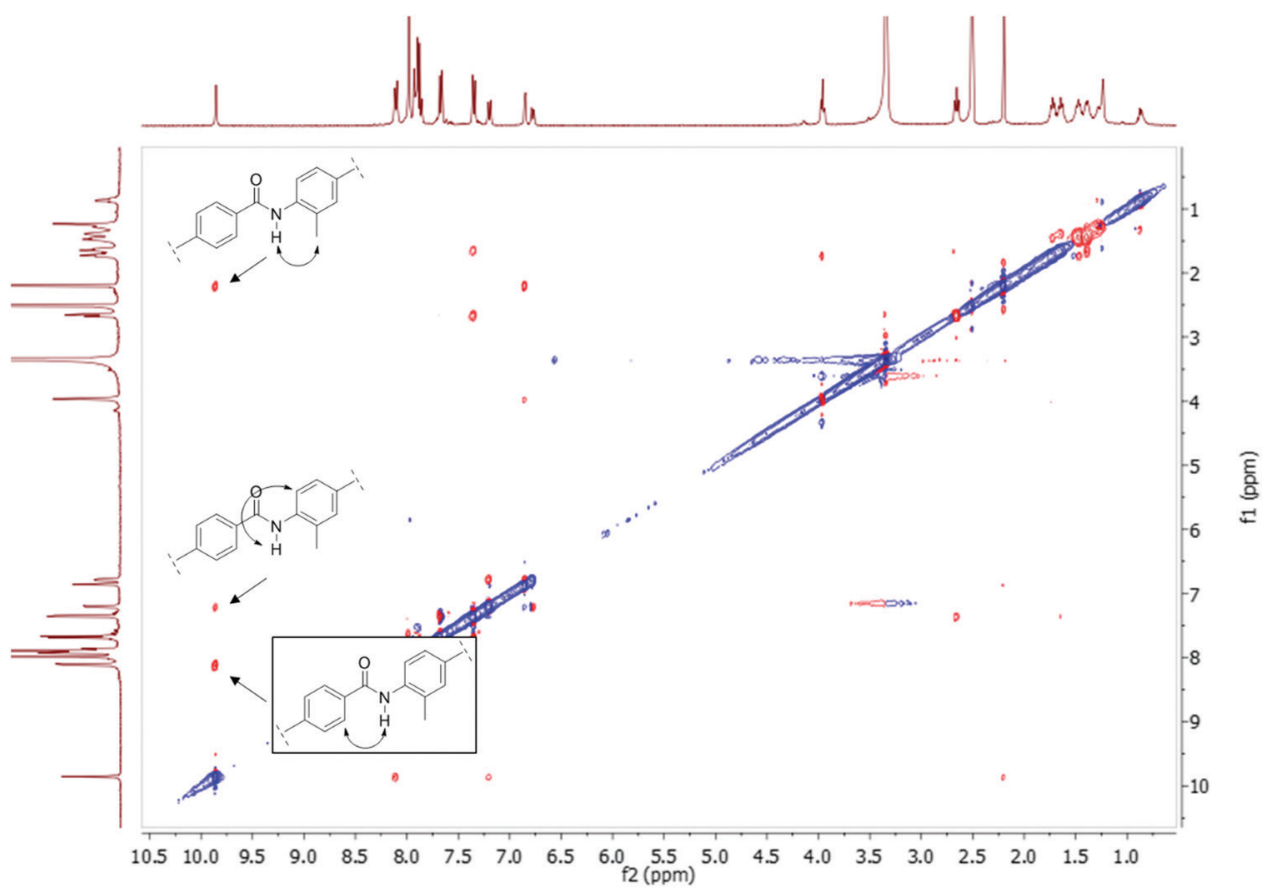

Fig. 9 2D ROESY Spectrum of compound 3a in DMSO.

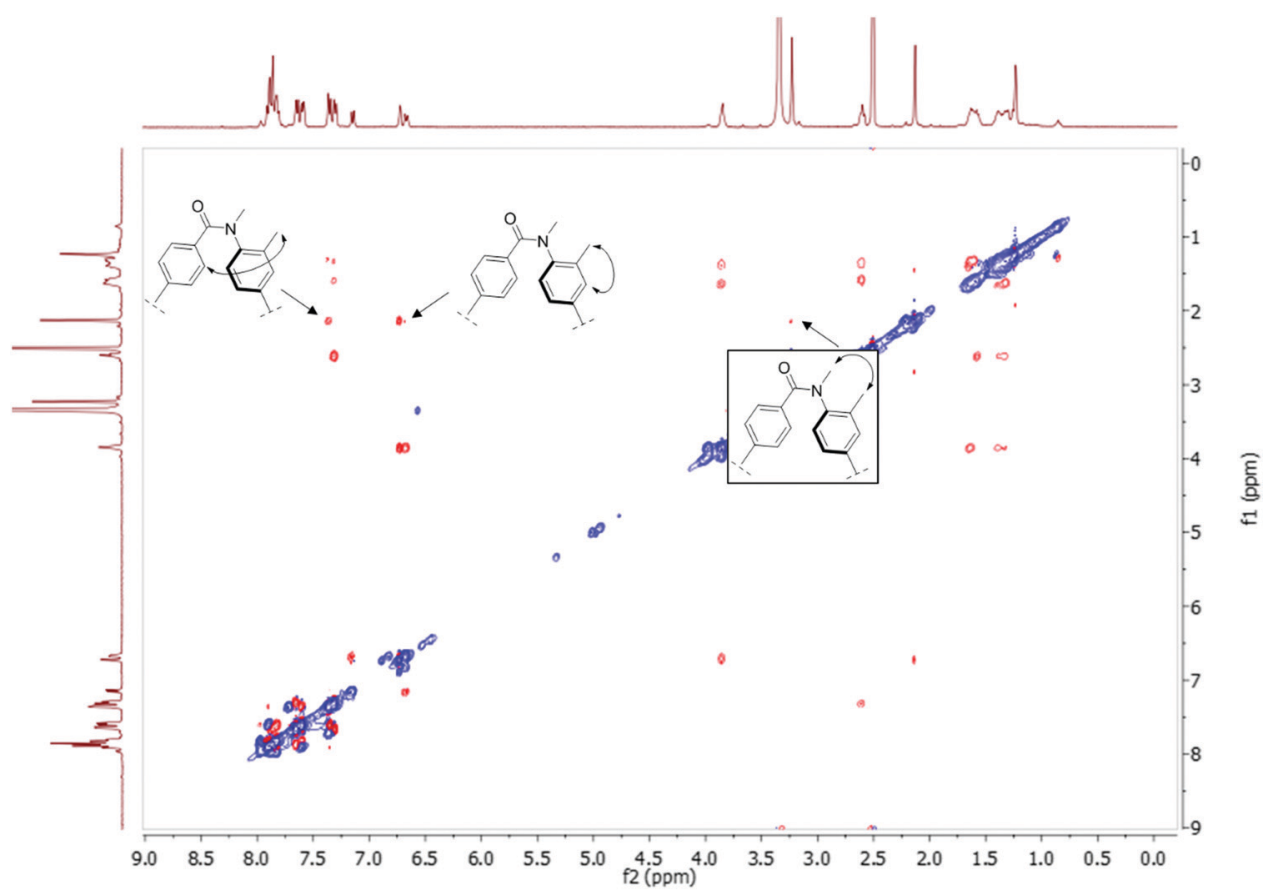

Fig. $102 \mathrm{D}$ ROESY Spectrum of compound $\mathbf{3 b}$ in DMSO.

structures of compounds $\mathbf{4 b}$ and $\mathbf{5 b}$ show that the amide group is entirely present as the $E$-conformer in the solid state. There are four unique $\mathrm{C}_{47} \mathrm{H}_{41} \mathrm{~N}_{3} \mathrm{O}_{2}$ molecules in the asymmetric unit of $\mathbf{4 b}$, with an example molecule illustrated in Fig. 12a, which shows its overall kinked shape, with the main twist occurring in the vicinity of the amide link. The O1a-C13a-N1a-C14a amide torsion angle of $0.3(9)^{\circ}$ shows that these atoms are statistically coplanar in a cis



Fig. 11 Left: DFT optimised Z-amide geometry of compound 4a. Right: The optimised E-amide geometry of compound $\mathbf{4 b}$. 
a)



c)



b)

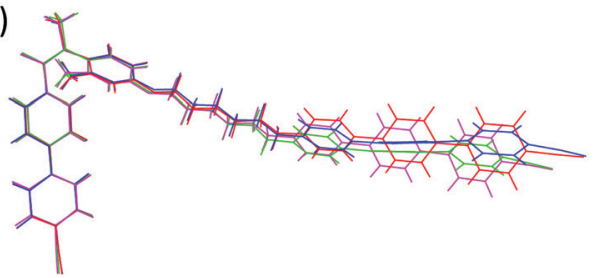

d)



Fig. 12 (a) The molecular structure of the C1a molecule in $\mathbf{4 b}$ showing $50 \%$ displacement ellipsoids. (b) Overlay plot of the four molecules in the asymmetric unit of $\mathbf{4 b}$. (c) Overlay plot of the C1a molecule (red) in $\mathbf{4 b}$ and its mirror image (blue) as generated by $\mathrm{c}$-glide crystal symmetry with the atoms of the C1a-C6a benzene rings overlapped. (d) The wave-like unit-cell packing for $\mathbf{4 b}$ viewed approximately down [100] with the four asymmetric molecules and their symmetry-generated clones shown in red, blue, green and yellow ( $\mathrm{H}$ atoms omitted for clarity).

conformation and the N1a-C15a-C16a-C21a torsion angle is 11.6(6) $)^{\circ}$ The hexyl chain adopts an extended (all anti) conformation and the dihedral angles subtended by the adjacent benzene rings C1a/C7a, C28a/C34a and C34a/C40a are 32.2(3), 23.6(3) and 18.2(2) respectively. The four asymmetric molecules have very similar conformations for their cyanobiphenyl ends, but their conformations increasingly diverge along the hexyl chains and the terphenyl units (Fig. 12b) as shown in an overlay plot generated with QMOL. ${ }^{65}$ Crystal symmetry in space group $C c$ generates a 50:50 mix of mirror images of each asymmetric molecule (Fig. 12c), where it may be seen that the $\mathrm{C} 21$ pendant methyl group of the benzene ring
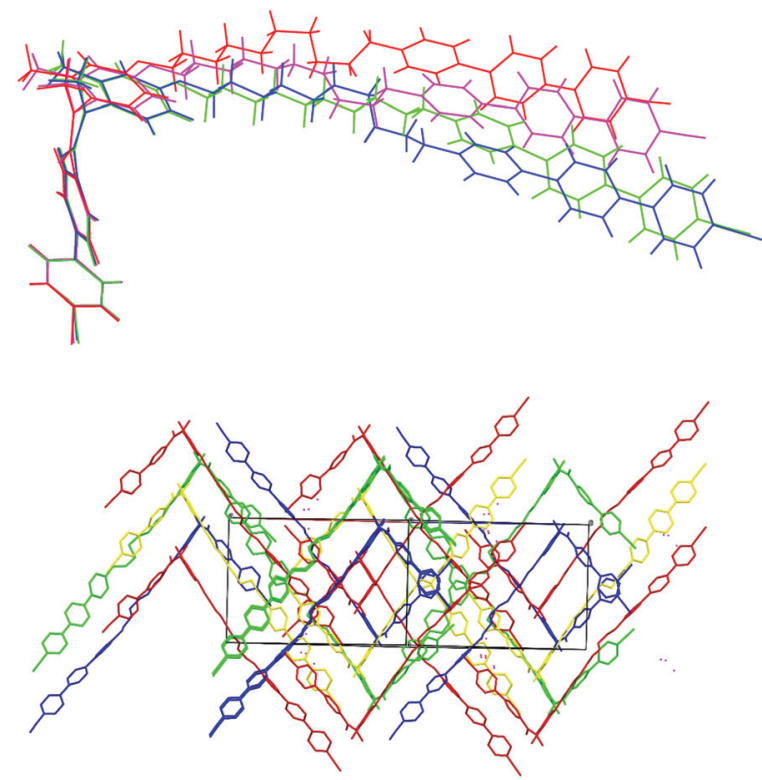

Fig. 13 Top: Overlay plot of the four molecules in the asymmetric unit of 5b. Below: The unit-cell packing for $\mathbf{5 b}$ viewed approximately down [101] with the four asymmetric molecules and their symmetry-generated clones shown in red, blue, green and yellow ( $\mathrm{H}$ atoms omitted for clarity). adjacent to the amide link lies to both the left- and right-hand sides of the molecules. When viewed down the [100] direction, the packing for $\mathbf{4 b}$ could be described as 'wave-like' (Fig. 12d).

The asymmetric unit of $\mathbf{5 b}$ also contains four unique $\mathrm{C}_{51} \mathrm{H}_{49} \mathrm{~N}_{3} \mathrm{O}_{2}$ molecules, which adopt similar but not identical conformations (Fig. 13), which may be described as L-shaped: again the cyanobiphenyl ends overlap well but there is increasing divergence along the decyl chains with some of the $\mathrm{C}-\mathrm{C}-\mathrm{C}-\mathrm{C}$ links in these chains adopting gauche conformations. As with $4 \mathbf{b}$, crystallographic symmetry (an $n$-glide in this case) generates equal numbers of mirror images in the crystal. The packing for $\mathbf{5 b}$ (Fig. 13) has a 'grid-like' appearance when viewed down [101].

Although the $3^{\circ}$ materials preferentially adopt the $E$-conformation in the solid state and in solution, the ${ }^{1} \mathrm{H}$ NMR spectra show an additional set of minor peaks which indicates the presence of a small amount of the $Z$-amide conformer. The ratio of major: minor peaks is dependent on the NMR solvent. To determine the rotational barrier around the $\mathrm{N}-\mathrm{C}(\mathrm{O})$ bond, the VT NMR experiment was repeated in deuterated DMF from 10-55 ${ }^{\circ} \mathrm{C}$, using compound $\mathbf{5 b}$ as a representative example, and the spectra are shown in Fig. 14.

Lineshape analysis was carried out using the DNMR option within TOPSPIN software to determine the rotational constant $k_{\text {rot }}$ at each temperature, and the free energy of rotation was determined using the Eyring equation. ${ }^{66}$ The rotational barrier was found to be $71.4 \pm 1.0 \mathrm{~kJ} \mathrm{~mol}^{-1}$. This is consistent with reported amide rotational barriers, which tend to fall between $63-84 \mathrm{~kJ} \mathrm{~mol}^{-1}$, and the error is in line with similar work. ${ }^{67}$

\section{Conclusions}

We have shown that there is a marked preference for the $E$ conformer in $3^{\circ}$ benzanilide dimers and this has been reported in the literature but not for liquid crystalline materials. The dramatic change in shape on methylation of the corresponding 



Fig. 14 Stacked VT NMR spectra of $\mathbf{5 b}$ in DMF showing coalescence of the minor peaks.

$2^{\circ}$ amide readily accounts for the dramatic difference seen in the liquid crystalline behaviour of the $2^{\circ}$ and $3^{\circ}$ dimers. Although intuitively pleasing, the disruption in hydrogen bonding need not be invoked to explain the thermal behaviour of these amides, although we do not exclude the possibility that it has some role to play in the reduction seen in $T_{\mathrm{NI}}$. Future attempts to incorporate benzanilides into new mesogenic moieties will require the structures to be designed based on the $E$-amide conformation.

\section{Conflicts of interest}

There are no conflicts to declare.

\section{References}

1 P. J. Collings and M. Hird, Introduction to liquid crystals: Chemistry and physics, CRC Press, 2017.

2 G. W. Gray, Liquid Crystals \& Plastic Crystals, 1974, vol. 1, pp. 103-153.

3 R. A. Vora and R. Gupta, A Homologous Series containing Ester and Amide Groups as Central Linkages: 4 (4'-n-Alkoxybenzoyloxy)- 4 " $-n$-Heptyloxy Benzanilides A Homologous Series containing Ester and Amide Groups as Central, Mol. Cryst. Liq. Cryst., 1981, 67, 215-220.

4 J. Belmar, M. Parra, C. Zuniga, C. Perez, C. Munoz, A. Omenat and J. L. Serrano, New liquid crystals containing the benzothiazol unit: Amides and azo compounds, Liq. Cryst., 1999, 26, 389-396.

5 M. Parra, J. Alderete, C. Zúñiga and S. Hernández, Liquid Crystals Synthesis, mesomorphic properties and structural study by semi-empirical calculations of amides containing the 1,3,4-thiadiazole unit, Liq. Cryst., 2002, 29, 647-652.

6 R. C. Tandel and R. A. Vora, Synthesis and study of 4-(4'-nalkoxybenzoyloxybenzoyl)-4"-n-butoxyanilides, Liq. Cryst., 2007, 34, 1369-1375.
7 T. Kajitani, S. Kohmoto, M. Yamamoto and K. Kishikawa, Generation of stable calamitic liquid-crystal phases with lateral intermolecular hydrogen bonding, Chem. Mater., 2004, 16, 2329-2331.

8 T. Kajitani, S. Kohmoto, M. Yamamoto and K. Kishikawa, Generation of Stable Calamitic Liquid-Crystal phases with Lateral Intermolecular Hydrogen Bonding, Angew. Chem., Int. Ed., 1999, 5, 859.

9 Q. C. Zhang, T. Takeda, N. Hoshino, S. I. Noro, T. Nakamura and T. Akutagawa, Liquid Crystalline Phase Induced by Molecular Rotator and Dipole Fluctuation, Cryst. Growth Des., 2015, 15, 5705-5711.

10 R. A. Vora and A. K. Prajapati, Liquid Crystalline Homologous Series with Biphenyl Nucleus, Mol. Cryst. Liq. Cryst. Sci. Technol. Sect. A Mol. Cryst. Liq. Cryst., 1999, 332, 329-338.

11 M. L. Parra, E. Y. Elgueta, V. Jimenez and P. I. Hidalgo, Novel amides and Schiff's bases derived from 1,3,4oxadiazole derivatives: Synthesis and mesomorphic behaviour, Liq. Cryst., 2009, 36, 301-317.

12 M. L. Parra, C. G. Saavedra, P. I. Hidalgo and E. Y. Elgueta, Novel chiral liquid crystals based on amides and azo compounds derived from 2-amino-1,3,4-thiadiazoles: synthesis and mesomorphic properties, Liq. Cryst., 2008, 35, 55-64.

$13 \mathrm{~J}$. Chu, L. Wu, Y. Guo, Y. Li, B. Li and Y. Yang, A series of fluorinated liquid crystals with an alanine residue, Liq. Cryst., 2020, 47, 465-470.

14 K. Gomola, L. Guo, D. Pociecha, F. Araoka, K. Ishikawa and H. Takezoe, An optically uniaxial antiferroelectric smectic phase in asymmetrical bent-core compounds containing a 3-aminophenol central unit, J. Mater. Chem., 2010, 20, 7944-7952.

15 G. Mohiuddin, S. Ghosh, N. Begum, S. Debnath, S. Turlapati, D. S. S. Rao and R. V. S. Nandiraju, Amide linkage in novel three-ring bent-core molecular assemblies: polar mesophases and importance of H-bonding, Liq. Cryst., 2018, 45, 1549-1566. 
16 V. Kozmík, M. Horčic, J. Svoboda, V. Novotná and D. Pociecha, 3-Aminophenol based bent-shaped liquid crystals with an amide linking group, Liq. Cryst., 2012, 39, 943-955.

17 S. Findeisen-Tandel, U. Baumeister, M.-G. Tamba and W. Weissflog, Bent-core Mesogens Containing Amide Linking Groups, Ferroelectrics, 2014, 468, 28-51.

18 A. Iqbal, H. M. Siddiqi, Z. Akhter and M. Qaiser Fatmi, Design and characterization of novel bis-benzamide liquid crystalline materials, J. Mol. Struct., 2018, 1151, 135-141.

19 I. Urbanaviciute, X. Meng, T. D. Cornelissen, A. V. Gorbunov, S. Bhattacharjee, R. P. Sijbesma and M. Kemerink, Tuning the Ferroelectric Properties of Trialkylbenzene-1,3,5tricarboxamide (BTA), Adv. Electron. Mater., 2017, 3, 1600530.

20 I. Urbanaviciute, S. Bhattacharjee, M. Biler, J. A. M. Lugger, T. D. Cornelissen, P. Norman, M. Linares, R. P. Sijbesma and M. Kemerink, Suppressing depolarization by tail substitution in an organic supramolecular ferroelectric, Phys. Chem. Chem. Phys., 2019, 21, 2069-2079.

21 M. L. Nguyen and B. Cho, Ferroelectrically Switchable Axial Polarization in Columnar Liquid Crystalline Phases, Chem. Eur. J., 2020, 26, 6964-6975.

22 C. F. C. Fitié, W. S. C. Roelofs, P. C. M. M. Magusin, M. Wübbenhorst, M. Kemerink and R. P. Sijbesma, Polar switching in trialkylbenzene-1,3,5-tricarboxamides, J. Phys. Chem. B, 2012, 116, 3928-3937.

23 B. Bai, C. Zhao, H. Wang, X. Ran, D. Wang and M. Li, Columnar mesophase from non-symmetrical tapered hydrazide derivatives, Mater. Chem. Phys., 2012, 133, 232-238.

24 B. Bai, X. Mao, Z. Xi, J. Ma, X. Lin, H. Wang and M. Li, Liquid crystalline behaviour of hydrazide derivatives containing alkoxyazobenzene, Liq. Cryst., 2014, 41, 214-221.

25 D. Pang, H. Wang and M. Li, Smectic A liquid crystals from dihydrazide derivatives with lateral intermolecular hydrogen bonding, Tetrahedron, 2005, 61, 6108-6114.

26 X. Ran, H. Wang, P. Zhang, B. Bai, C. Zhao, Q. Zhang, H. Liu, $\mathrm{Z}$. Yu and M. Li, Anticlinic smectic phase formed by calamitic hydrazide derivatives with terminal hydroxyl group, Liq. Cryst., 2011, 38, 1227-1237.

27 C. Zhang, X. Che, T. Zhang, B. Bai, H. Wang and M. Li, Solvent-dependent gelation behaviour and liquid crystal properties of a bent-core dihydrazide derivative, New J. Chem., 2017, 41, 9482-9488.

28 H. Wang, B. Bai, D. Pang, Z. Zou, L. Xuan, F. Li, P. Zhang, L. Liu, B. Long and M. Li, Synthesis and liquid crystalline properties of hydrazide derivatives: hydrogen bonding, molecular dipole, and smectic structures, Liq. Cryst., 2008, 35, 333-338.

29 K. Kishikawa, S. Nakahara, Y. Nishikawa, S. Kohmoto, M. Yamamoto, K. Kishikawa, S. Nakahara, Y. Nishikawa, A. S. Kohmoto and M. Yamamoto, A Ferroelectrically Switchable Columnar Liquid Crystal Phase with Achiral Molecules: Superstructures and Properties of Liquid Crystalline Ureas, J. Am. Chem. Soc., 2005, 127, 2565-2571.

30 S. Parthasarathi, D. S. Shankar Rao, R. Prabhu, C. V. Yelamaggad and S. Krishna Prasad, Influence of chirality on the thermal and electric properties of the columnar mesophase exhibited by homomeric dipeptides, J. Chem. Phys., 2017, 147, 134905.

31 R. Prabhu, C. V. Yelamaggad and G. Shanker, Selforganisation properties of homomeric dipeptides derived from valine, Liq. Cryst., 2014, 41, 1008-1016.

32 J. A. Duro, G. De La Torre, J. Barberá, J. L. Serrano and T. Torres, Synthesis and liquid-crystal behavior of metal-free and metal-containing phthalocyanines substituted with long-chain amide groups, Chem. Mater., 1996, 8, 1061-1066.

33 U. Stebani, G. Lattermann, R. Festag, M. Wittenberg and J. H. Wendorff, A novel class of mesogens: liquid-crystalline derivatives of linear oligoalkylene amides, J. Mater. Chem., 1995, 5, 2247.

34 B. Glettner, S. Hein, R. A. Reddy, U. Baumeister and C. Tschierske, Cyclic ureas as novel building blocks for bentcore liquid crystals, Chem. Commun., 2007, 2596-2598.

35 D. Pociecha, J. Szydłowska, J. Gassowska, D. Karda, J. Mieczkowski and W. Tłaczała, New mesogenic compounds having fork-like or cyclic amide terminal groups, Liq. Cryst., 2002, 29, 663-667.

36 S. L. Wu and F. D. Chen, Novel chiral swallow-tailed amide liquid crystals possessing antiferroelectricity, Liq. Cryst., 2003, 30, 991-995.

$37 \mathrm{~S}$. Wu, Z. Yang and L. Yu, Antiferroelectric liquid crystals with amide linking group positioned at chiral tail, Liq. Cryst., 2007, 34, 1145-1149.

38 L. Chabaud, J. Clayden, M. Helliwell, A. Page, J. Raftery and L. Vallverdú, Conformational studies of tertiary oligom-benzanilides and oligo- $p$-benzanilides in solution, Tetrahedron, 2010, 66, 6936-6957.

39 S. Saito, Y. Toriumi, N. Tomioka and A. Itai, Theoretical Studies on cis-Amide Preference in N-Methylanilides, J. Org. Chem., 1995, 60, 4715-4720.

40 A. Itai, Y. Toriumi, N. Tomioka, H. Kagechika, I. Azumaya and K. Shudo, Stereochemistry of N-methylbenzanilide and benzanilide, Tetrahedron Lett., 1989, 30, 6177-6180.

41 S. Kashino, K. Ito and M. Haisa, Bull. Chem. Soc. Jpn., 1979, 52, 365-369.

42 C. T. Imrie and P. A. Henderson, Liquid crystal dimers and higher oligomers: Between monomers and polymers, Chem. Soc. Rev., 2007, 36, 2096-2124.

43 C. T. Imrie, P. A. Henderson and G. Y. Yeap, Liquid crystal oligomers: Going beyond dimers, Liq. Cryst., 2009, 36, $755-777$.

44 I. Dozov, On the spontaneous symmetry breaking in the mesophases of achiral banana-shaped molecules, Europhys. Lett., 2001, 56, 247-253.

45 M. Cestari, S. Diez-Berart, D. A. Dunmur, A. Ferrarini, M. R. de la Fuente, D. J. B. Jackson, D. O. Lopez, G. R. Luckhurst, M. A. Perez-Jubindo, R. M. Richardson, J. Salud, B. A. Timimi and H. Zimmermann, Phase behavior and properties of the liquid-crystal dimer $1^{\prime \prime}, 7^{\prime \prime}$-bis(4-cyanobiphenyl-4'yl) heptane: A twist-bend nematic liquid crystal, Phys. Rev. E, 2011, 84, 031704.

46 P. A. Henderson and C. T. Imrie, Methylene-linked liquid crystal dimers and the twist-bend nematic phase, Liq. Cryst., 2011, 38, 1407-1414. 
47 V. Borshch, Y.-K. Kim, J. Xiang, M. Gao, A. Jákli, V. P. Panov, J. K. Vij, C. T. Imrie, M. G. Tamba, G. H. Mehl and O. D. Lavrentovich, Nematic twist-bend phase with nanoscale modulation of molecular orientation, Nat. Commun., 2013, 4, 2365.

48 R. Walker, D. Pociecha, J. M. D. Storey, E. Gorecka and C. T. Imrie, The Chiral Twist-Bend Nematic Phase $\left(\mathrm{N}^{*} \mathrm{~TB}\right)$, Chem. - A Eur. J., 2019, 25, 13329-13335.

49 D. A. Paterson, M. Gao, Y.-K. Kim, A. Jamali, K. L. Finley, B. Robles-Hernández, S. Diez-Berart, J. Salud, M. R. de la Fuente, B. A. Timimi, H. Zimmermann, C. Greco, A. Ferrarini, J. M. D. Storey, D. O. López, O. D. Lavrentovich, G. R. Luckhurst and C. T. Imrie, Understanding the twist-bend nematic phase: the characterisation of 1-(4-cyanobiphenyl-4'-yloxy)-6-(4-cyanobiphenyl-4'-yl)hexane (CB6OCB) and comparison with CB7CB, Soft Matter, 2016, 12, 6827-6840.

50 R. Walker, D. Pociecha, G. J. Strachan, J. M. D. Storey, E. Gorecka and C. T. Imrie, Molecular curvature, specific intermolecular interactions and the twist-bend nematic phase: the synthesis and characterisation of the 1-(4-cyanobiphenyl-4'yl)-6-(4-alkylanilinebenzylidene-4'-oxy)hexanes (CB6O.m), Soft Matter, 2019, 15, 3188-3197.

51 R. J. Mandle, C. T. Archbold, J. P. Sarju, J. L. Andrews and J. W. Goodby, The Dependency of Nematic and Twist-bend Mesophase Formation on Bend Angle, Sci. Rep., 2016, 6, 36682 .

52 Y. Arakawa, K. Komatsu, S. Inui and H. Tsuji, Thioetherlinked liquid crystal dimers and trimers: The twist-bend nematic phase, J. Mol. Struct., 2020, 1199, 126913.

53 G. M. Sheldrick, SHELXT - Integrated space-group and crystal-structure determination, Acta Cryst., 2015, 71, 3-8.

54 M. J. Frisch, G. W. Trucks, H. B. Schlegel, G. E. Scuseria, M. A. Robb, J. R. Cheeseman, G. Scalmani, V. Barone, G. A. Petersson, H. Nakatsuji, X. Li, M. Caricato, A. Marenich, J. Bloino, B. G. Janesko, R. Gomperts, B. Mennucci, H. P. Hratchian, J. V. Ortiz, A. F. Izmaylov, J. L. Sonnenberg, D. Williams-Young, F. Ding, F. Lipparini, F. Egidi, J. Goings, B. Peng, A. Petrone, T. Henderson, D. Ranasinghe, V. G. Zakrzewski, J. Gao, N. Rega, G. Zheng, W. Liang, M. Hada, M. Ehara, K. Toyota, R. Fukuda, J. Hasegawa, M. Ishida, T. Nakajima, Y. Honda, O. Kitao, H. Nakai, T. Vreven, K. Throssell, J. J. A. Montgomery, J. E. Peralta, F. Ogliaro, M. Bearpark, J. J. Heyd, E. Brothers, K. N. Kudin, V. N. Staroverov, T. Keith, R. Kobayashi, J. Normand, K. Raghavachari, A. Rendell, J. C. Burant, S. S. Iyengar, J. Tomasi, M. Cossi, J. M. Millam, M. Klene, C. Adamo, R. Cammi, J. W. Ochterski, R. L. Martin, K. Morokuma,
O. Farkas, J. B. Foresman and D. J. Fox, Gaussian 09, Gaussian, Inc., Wallingford CT, 2016.

55 M. Tarini, P. Cignoni and C. Montani, Ambient Occlusion and Edge Cueing to Enhance Real Time Molecular Visualization, IEEE Trans. Vis. Comp. Graph., 2006, 12, 1237-1244.

56 D. A. Paterson, J. P. Abberley, W. T. A. Harrison, J. Storey and C. T. Imrie, Cyanobiphenyl-based liquid crystal dimers and the twist-bend nematic phase, Liq. Cryst., 2017, 44, 127-146.

57 J. W. Emsley, G. De Luca, A. Lesage, D. Merlet and G. Pileio, The structure and conformation of a mesogenic compound between almost zero and almost complete orientational order, Liq. Cryst., 2007, 34, 1071-1093.

58 E. Cruickshank, M. Salamończyk, D. Pociecha, G. J. Strachan, J. M. D. Storey, C. Wang, J. Feng, C. Zhu, E. Gorecka and C. T. Imrie, Sulfur-linked cyanobiphenyl-based liquid crystal dimers and the twist-bend nematic phase, Liq. Cryst., 2019, 46, 1595-1609.

59 Z. Lu, P. A. Henderson, B. J. A. Paterson and C. T. Imrie, Liquid crystal dimers and the twist-bend nematic phase. The preparation and characterisation of the $\alpha, \omega$-bis(4-cyanobiphenyl-4'-yl) alkanedioates, Liq. Cryst., 2014, 41, 471-483.

60 C. T. Imrie, Laterally substituted dimeric liquid crystals, Liq. Cryst., 1989, 6, 391-396.

61 A. J. Leadbetter, P. A. Tucker, G. W. Gray, A. R. Tajbakhsh, P. A. Tucker, G. W. Gray and A. R. Tajbakhsh, Unusual structures in some alkyl cyanoterphenyls, Liq. Cryst., 1990, 8, 1-12.

62 R. Walker, D. Pociecha, J. M. D. Storey, E. Gorecka and C. T. Imrie, Remarkable smectic phase behaviour in oddmembered liquid crystal dimers: The CT6O.m series, J. Mater. Chem. C, 2021, 9, 5167-5173.

63 T. Donaldson, H. Staesche, Z. B. Lu, P. A. Henderson, M. F. Achard and C. T. Imrie, Symmetric and non-symmetric chiral liquid crystal dimers, Liq. Cryst., 2010, 37, 1097-1110.

64 T. N. Chan, Z. Lu, W. S. Yam, G. Y. Yeap and C. T. Imrie, Non-symmetric liquid crystal dimers containing an isoflavone moiety, Liq. Cryst., 2012, 39, 393-402.

65 J. D. Gans and D. Shalloway, Qmol: a program for molecular visualization on Windows-based PCs, J. Mol. Graph. Model., 2001, 19, 557-559.

66 J. Sandström, Dynamic NMR Spectroscopy, Academic Press Inc., 1982.

67 A. J. Clark, D. P. Curran, D. J. Fox, F. Ghelfi, C. S. Guy, B. Hay, N. James, J. M. Phillips, F. Roncaglia, P. B. Sellars, P. Wilson and H. Zhang, Axially Chiral Enamides: Substituent Effects, Rotation Barriers, and Implications for their Cyclization Reactions, J. Org. Chem., 2016, 81, 5547-5565. 